BRE 11524

\title{
Two Opioid Forms of Stress Analgesia: Studies of Tolerance and Cross-Tolerance
}

\author{
GREGORY W. TERMAN ${ }^{1}$, JAMES W. LEWIS² and JOHN C. LIEBESKIND ${ }^{1}$ \\ 'Department of Psychology, University of California, Los Angeles, Los Angeles, CA 90024 and \\ ${ }_{2}^{2}$ Mental Health Research Institute, University of Michigan, Ann Arbor, MI 48109 (U.S.A.)
}

(Accepted July 23rd, 1985)

Key words: stress analgesia — tolerance — cross-tolerance — opioid — non-opioid - morphine

\begin{abstract}
We have previously reported that stress analgesia sensitive to and insensitive to opiate antagonists can be differentially produced in rats by varying the severity or temporal pattern of inescapable footshock. In these studies, we give further evidence for the opioid and non-opioid bases of these paradigms of stress analgesia. We find that naloxone-sensitive analgesia demonstrates tolerance with repeated stress and cross-tolerance with morphine, whereas naloxone-insensitive analgesia demonstrates neither of these characteristics. Moreover, different forms of opioid, but not non-opioid, stress analgesia manifest cross-tolerance with each other. These data are discussed in terms of the similarities and differences between two forms of opioid stress analgesia.
\end{abstract}

\section{INTRODUCTION}

Multiple pain-inhibitory systems appear to exist in the rat that function via descending influences from the brain to the spinal cord ${ }^{36,39}$. It has been proposed that activation of such systems underlies the analgesic effects of such experimental and clinical procedures as electrical brain stimulation $26,29,40$, acupuncture $^{25}$, placebo ${ }^{15}$, and the administration of opiate drugs $^{26}$. The finding that various stressors (including thermal challenge ${ }^{3.6,14}$, restraint ${ }^{2}$, hypoglycemia ${ }^{4.27}$, conspecific defeat ${ }^{28}$ and electric shock ${ }^{1,5,9}$ ) markedly reduce pain responsiveness suggested that stress is a natural trigger for activation of these endogenous pain-inhibitory substrates. Stress-induced analgesia, however, has proven to be a complex phenomenon. For example, some of the original studies found that stress analgesia from footshock was blocked by the opiate antagonist, naloxone 1.5 and demonstrated cross-tolerance with morphine 5 . Such findings indicated that endogenous opioid peptides mediate stress analgesia. By application of these same criteria, however, other early studies using footshock found stress analgesia to be independent of opioids ${ }^{9}$.

In our initial work, using inescapable footshock, we reported that opioid and non-opioid mechanisms of stress analgesia could be differentially activated by varying the temporal parameters of the stressor ${ }^{16}$. More specifically, whereas $20-30 \mathrm{~min}$ of $2.5-3.0 \mathrm{~mA}$ intermittent footshock ( $1 \mathrm{~s}$ on every $5 \mathrm{~s}$ ) elicited analgesia sensitive to low doses of opiate antagonists and manifesting tolerance with repeated stress exposure and cross-tolerance with morphine, 3 min of continuous footshock at these same intensities yielded an equipotent analgesia showing none of these characteristics ${ }^{16.18 .19}$. Other investigators have also reported differential production of opioid and non-opioid forms of stress analgesia using these same criteria for opioid mediation ${ }^{8.37 .39}$. Further emphasizing the separateness of the substrates underlying opioid and non-opioid forms of stress analgesia, we found no cross-tolerance between them ${ }^{32}$. That is, repeated exposure to one stress paradigm did not reduce the analgesic effect of initial exposure to the other.

We have recently reported that a second form of stress analgesia sensitive to low doses of opiate antagonists can be produced by continuous footshock of briefer duration or lower intensity than that producing non-opioid analgesia ${ }^{33}, 36$. The purpose of the present experiment was to determine whether this

Correspondence: J.C. Liebeskind, Department of Psychology, University of California, Los Angeles, Los Angeles, CA 90024, U.S.A. 
second naloxone-sensitive form of stress analgesia met other criteria of opioid mediation. We began by testing for cross-tolerance between morphine and several paradigms of naloxone-sensitive and naloxone-insensitive continuous footshock stress analgesia.

\section{EXPERIMENT 1}

\section{Methods}

Thirty male Sprague-Dawley rats $(400-450 \mathrm{~g})$ were purchased from Simonsen Laboratories and randomly divided into two groups. One group was given daily injections of morphine $(10 \mathrm{mg} / \mathrm{kg}$, s.c.) for the duration of the experiment. The other group received daily injections of isotonic saline for the same time period. After 7 days of injections, all rats were exposed to $1 \mathrm{~min}$ of continuous footshock, $4 \mathrm{~min}$ of continuous footshock, and $20 \mathrm{~min}$ of intermittent ( $1 \mathrm{~s}$ on every $5 \mathrm{~s}$ ) footshock on successive days in counterbalanced order. Footshock consisted of 2.5 $\mathrm{mA} 60 \mathrm{~Hz}$ sine waves administered through the grid floor of a $20 \times 23 \times 20 \mathrm{~cm}$ Plexiglas chamber. These 3 stress paradigms, differing in their temporal parameters, have previously been shown to yield 'opioid' ( 1 and $20 \mathrm{~min}$ ) and 'non-opioid' (4 min) stress analgesia as defined by sensitivity to opiate antagonists ${ }^{36}$.

In a separate experiment, 20 additional rats were divided into two equal groups and injected with either morphine $(10 \mathrm{mg} / \mathrm{kg}$, s.c.) or saline daily for the duration of the experiment. On days 8 and 9 , all animals were exposed to 3 min of footshock at 2.0 $\mathrm{mA}$ and $3.5 \mathrm{~mA}$ in counterbalanced order. We have previously shown that these two footshock paradigms, differing in shock intensity, yield analgesia that is sensitive $(2.0 \mathrm{~mA})$ and insensitive $(3.5 \mathrm{~mA})$ to opiate antagonists ${ }^{36}$.

Pain responsiveness was assessed by the tail-flick test $^{7}$. We $\mathrm{W}^{19,36}$ and others have used a variety of analgesiometric methods in studies of stress analgesia assuring that the basic phenomenon has generality across tests. Prestress baselines were defined as the mean of the last 3 of 5 tail-flick trials. Ten poststress tail-flick latencies were taken at $1 \mathrm{~min}$ intervals beginning 1 min after footshock cessation. Exposure to the radiant heat source for any one tail-flick trial was limited to $7 \mathrm{~s}$ to minimize tissue damage.

Data were analyzed using separate 2-way (group

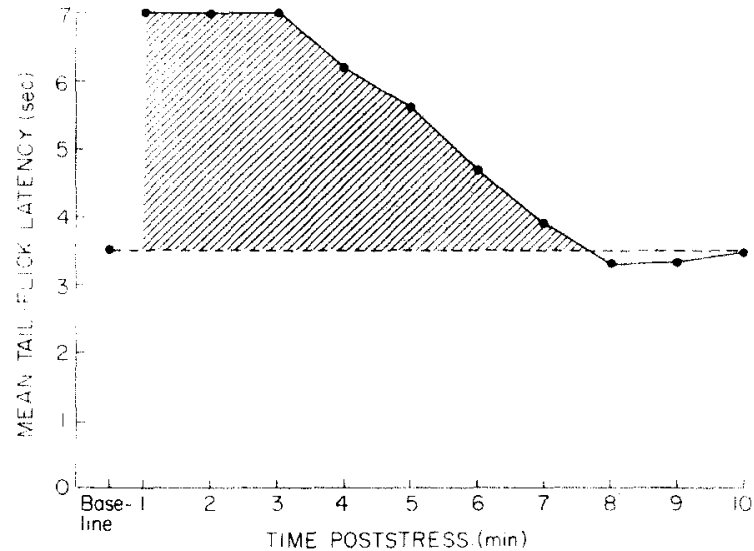

Fig. 1. Diagrammatic representation of how analgesia scores were calculated for each animal. Tail-flick latencies were plotted for each of the 10 poststress trials. Analgesia score was defined as the area under the resultant curve, using the animal's baseline latency as the ordinate's zero point (hatched area).

$\times$ trials) analyses of variance for each stress analgesia paradigm. For illustrative purposes only, results were converted to 'analgesia scores' calculated for each animal as follows: tail-flick latencies were plotted for each of the 10 poststress trials. The analgesia score was defined as the area under the resultant curve, using that animal's baseline latency as the ordinate's zero point (Fig. 1).



Fig. 2. Stress analgesia elicited in morphine-tolerant and saline-treated controls by several footshock paradigms. A: morphine-tolerant animals demonstrate significantly less analgesia than controls (cross-tolerance) when shocked with 1 min of continuous or $20 \mathrm{~min}$ of intermittent $2.5 \mathrm{~mA}$ footshock but not 4 min of continuous footshock at this same intensity. B: morphine-tolerant animals also demonstrate significant cross-tolerance when shocked with $2.0 \mathrm{~mA}$, but not $3.5 \mathrm{~mA}$, footshock for $3 \mathrm{~min}$. 


\section{Results}

Morphine tolerant animals showed significantly less stress analgesia than saline controls after both $1 \mathrm{~min}$ of continuous and $20 \mathrm{~min}$ of intermittent footshock at $2.5 \mathrm{~mA}$ (Fig. 2A). In contrast, morphine tolerant animals did not differ from saline controls in analgesia elicited by $4 \mathrm{~min}$ of continuous $2.5 \mathrm{~mA}$ footshock (Fig. 2A). These data demonstrate analgesic cross-tolerance between morphine and the two naloxone-sensitive forms, but not the naloxone-insensitive form, of stress analgesia ${ }^{36}$. They replicate our previous finding of morphine cross-tolerance with analgesia from long-duration, intermittent footshock ${ }^{19}$ and give further evidence for the opioid nature of stress analgesia from $1 \mathrm{~min}$ of continuous footshock.

Animals made tolerant to morphine also manifested cross-tolerance to analgesia from $3 \mathrm{~min}$ of continuous footshock at $2.0 \mathrm{~mA}$ (Fig. 2B), parameters known to cause analgesia sensitive to an opiate antagonist ${ }^{36}$. Cross-tolerance was not seen between morphine and analgesia from the more intense 3.5 $\mathrm{mA}$ footshock paradigm known to elicit analgesia insensitive to an opiate antagonist ${ }^{36}$.

\section{EXPERIMENT 2}

The results of experiment 1 demonstrate that cross-tolerance with morphine, like sensitivity to opiate antagonists ${ }^{36}$, can be differentially affected by variations in the temporal or intensive parameters of footshock. Less severe (briefer or less intense) continuous footshock, as well as long duration, intermittent footshock, were seen to evoke opioid-mediated stress analgesia, whereas more severe (longer or more intense) continuous footshock caused nonopioid stress analgesia. The question remained whether the two different paradigms of opioid stress analgesia share a common opioid substrate. Experiment 2 addressed this question by investigating whether the two opioid forms of analgesia, and only these forms, manifest tolerance with repetition and cross-tolerance with each other.

\section{Methods}

Thirty rats were randomly assigned to 3 equal groups. On day 1, groups were stressed using $1 \mathrm{~min}$ of continuous, $4 \mathrm{~min}$ of continuous or $20 \mathrm{~min}$ of inter- mittent $2.5 \mathrm{~mA}$ footshock and assessed for analgesia as described in experiment 1 . All animals were then stressed daily for 14 more days, using the same footshock parameters to which they had been exposed on day 1 . On day 15 , analgesia was measured again to assess tolerance. On the next two days, all rats were exposed in counterbalanced order to the two shock paradigms they had not yet experienced and tested for analgesia once again to assess cross-tolerance.

Results were analyzed using two separate analyses of variance for each shock paradigm. The cross-tolerance data were analyzed using a 2-way analysis of variance (group $\times$ trials) with one repeated measure, as before. The tolerance data were analyzed using a 2-way analysis of variance (session $\times$ trials) with two repeated measures. Tukey's tests were used for appropriate posthoc comparisons ${ }^{11}$. Analgesia scores were again calculated for each animal.

Twenty additional rats were divided into two equal groups. One group was administered 1 min of continuous $2.5 \mathrm{~mA}$ footshock daily for 14 days, whereas the other group served as non-shocked controls. On day 15 and 16, all animals were exposed to 3 min of continuous footshock at $2.0 \mathrm{~mA}$ and $3.5 \mathrm{~mA}$ in counterbalanced order and tested for analgesia as before. Data were analyzed using a 2-way analysis of variance with one repeated measure.

\section{Results}

Animals given 14 daily sessions of $1 \mathrm{~min}, 2.5 \mathrm{~mA}$ continuous footshock manifested tolerance to that form of stress analgesia, demonstrating significantly less analgesia on day 15 than on day $1(P<0.05)$ (Fig. 3A). In accordance with our earlier report ${ }^{19}$, rats shocked repeatedly with 20 min of intermittent footshock also manifested significant tolerance $(P<$ 0.05 ) (Fig. 3A). In contrast, animals exposed to 4 min of continuous $2.5 \mathrm{~mA}$ footshock did not show significant tolerance (Fig. 3A). This non-opioid form of stress analgesia also failed to show cross-tolerance to either of the other two stress paradigms (Fig. 3A). That is, animals given 15 days of the 4 min footshock did not differ from naive animals in analgesia elicited by the 1 or 20 min paradigms (Fig. 3A), and animals receiving 15 sessions of either of these latter two paradigms did not differ from naive animals in stress analgesia elicited by the 4 min footshock.

Of particular interest, the 1 and 20 min opioid par- 


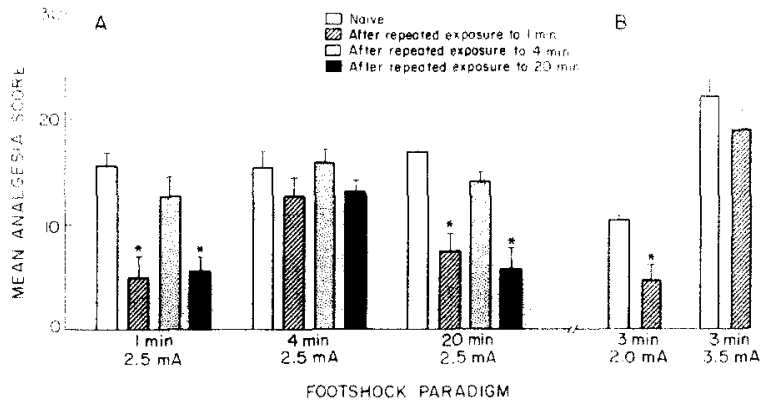

Fig. 3. Stress analgesia elicited by several paradigms of footshock in naive control rats and rats previously shocked repeatedly with either $1 \mathrm{~min}$ of continuous, $4 \mathrm{~min}$ of continuous or 20 min of intermittent footshock (2.5 mA). A: animals previously shocked repeatedly with either the 1 or 20 min paradigm showed significantly less analgesia than controls when shocked on the test day with the 1 or 20 min but not the 4 min paradigm. Animals previously shocked repeatedly with the 4 min paradigm showed analgesia not different from controls when shocked on the test day with any of these paradigms. B: animals previously shocked repeatedly using the $1 \mathrm{~min}$ paradigm showed significantly less analgesia than controls when shocked with the $2.0 \mathrm{~mA}$, but not the $3.5 \mathrm{~mA}, 3 \mathrm{~min}$ continuous footshock.

adigms, which produce analgesia showing both naloxone-sensitivity ${ }^{36}$ and cross-tolerance with morphine (experiment 1), also manifest cross-tolerance with each other. That is, animals given repeated exposure to either $1 \mathrm{~min}$ continuous or $20 \mathrm{~min}$ intermittent footshock showed significantly less analgesia than naive controls when exposed to the other one ( $P$ $<0.05$ ) (Fig. 3A). This cross-tolerance between opioid forms of stress analgesia suggests that they not only share a common neurochemical basis, as suggested by experiment 1 , but that they also share a common site of action for this neurochemistry.

Similarly, cross-tolerance developed between the opioid forms of stress analgesia elicited by $1 \mathrm{~min}$ of $2.5 \mathrm{~mA}$ continuous footshock and $3 \mathrm{~min}$ of $2.0 \mathrm{~mA}$ continuous footshock. Thus, animals repeatedly shocked with the former stress paradigm showed significantly less analgesia when shocked with the latter than did naive controls $(P<0.05)$ (Fig. 3B). Such cross-tolerance was not apparent with the $3 \mathrm{~min}, 3.5$ $\mathrm{mA}$ non-opioid stress analgesia paradigm (Fig. 3B).

\section{DISCUSSION}

In experiment 1 , analgesia from the less severe (lower intensity or briefer duration), but not the more severe, continuous footshock paradigms was reduced in morphine-tolerant rats. This demonstrittion of differential cross-tolerance with morphine extends our previous findings using opiate antagonist drugs 33,36 suggesting that opioid and non-opioid forms of stress analgesia can be reliably produced by varying the severity of continuous footshock. We previously found, and confirm here, that opioid and non-opioid forms of stress analgesia also derive from varying the temporal pattern of footshock (long-duration intermittent vs brief continuous $)^{\text {in } .3 n}$. Thus, in experiment 1 , analgesia from $20 \mathrm{~min}$ of intermittent ( $1 \mathrm{~s}$ on every $5 \mathrm{~s}$ ) footshock manifested cross-tolerance with morphine, whereas that from the same intensity and total duration of continuous footshock ( 4 min) did not.

The results of experiment 2 provide additional evidence for the opioid and non-opioid bases of the anatgesia caused by footshocks that differ in their severity or temporal pattern. Analgesia from less severe continuous footshock and from prolonged intermittent footshock manifested tolerance with repetition and cross-tolerance with each other. Our recent finding that these paradigms of stress analgesia show crosstolerance with naloxone-sensitive analgesia produced by stimulation of the rat periaqueductal gray matter ${ }^{35}$, also is consistent with the view that these forms of stress analgesia are opioid mediated. By contrast, analgesia from the more severe continuous footshock paradigms tested in experiment 2 manifests neither tolerance nor cross-tolerance with any other paradigm of stress analgesia nor with stimulation-produced analgesia ${ }^{35}$. These findings, as well as those of experiment 1 demonstrating no cross-tolerance between morphine and such non-opioid stress analgesia emphasize the possible clinical implications of understanding the mechanisms underlying this analgesia. Unfortunately, such investigations have not yet yielded definitive answers about the neurochemical mediation of non-opioid forms of stress analgesia, although histamine $20,310,31$, acetylcholine ${ }^{\text {i⿱ }}$, dopamine ${ }^{10}$ and serotonin ${ }^{10}$ have all been implicated.

The fact that cross-tolerance develops between opioid forms of stress analgesia from continuous and intermittent footshock (experiment 2) points to a common neural substrate involved in their mediation. The locus of this substrate has yet to be determined: both brain and spinal cord seem to be impor- 
tant since analgesia from all stress paradigms examined thus far are reduced by thoracic spinal lesions $13,21,36$. Despite their similarities, the two paradigms of opioid stress analgesia also differ from one another in several respects. Whereas opioid analgesia from prolonged intermittent footshock appears to rely on adrenal medullary enkephalins ${ }^{22}$, central cholinergic mechanisms ${ }^{17}$, and the integrity of the forebrain ${ }^{13,36}$, opioid analgesia from continuous footshock relies solely on opioids of central origin (independent of pituitary and adrenal glands) ${ }^{36}$ and is unaffected by cholinergic receptor blockade ${ }^{34}$, decerebration ${ }^{13,36}$ and deep pentobarbital anesthesia ${ }^{36}$. The stimuli activating these neurally, hormonally and neurochemically discrete opioid systems appear to differ. Whereas opioid stress analgesia from prolonged intermittent footshock seems to depend on the animal's learning that the stressor is inescapable $23.24,36$, opioid stress analgesia from continuous footshock seems to depend primarily on the physical properties of the stressor (i.e. duration or intensity) rather than higher brain processing 13,36 or even perception of the stressor as 'stressful' 36 .

Recalling that analgesia from 4 min of footshock shows no tolerance with repetition whereas that from $1 \mathrm{~min}$ of footshock does, it is intriguing to note that

\section{REFERENCES}

1 Akil, H., Madden, J., Patrick, R.L. and Barchas, J.D., Stress-induced increase in endogenous opiate peptides: concurrent analgesia and its partial reversal by naloxone. In H.W. Kosterlitz (Ed.), Opiates and Endogenous Opioid Peptides, Elsevier, Amsterdam, 1976, pp. 63-70.

2 Amir, S. and Amit, Z., Endogenous opioid ligands may mediate stress-induced changes in the affective properties of pain related behavior in rats, Life Sci., 23 (1978) $1143-1152$.

3 Bodnar, R.J., Kelly, D.D., Spiaggia, A., Ehrenberg, C. and Glusman, M., Dose-dependent reductions by naloxone of analgesia induced by cold-water stress, Pharmacol. Biochem. Behav., 8 (1978) 667-672.

4 Bodnar, R.J., Kelly, D.D., Brutus, M. and Glusman, M., 2-Deoxy-D-glucose treatment: adaptation of its analgesic, but not hyperphagic properties, Pharmacol. Biochem. Behav., $9(1978) 763-768$.

5 Chesher, G.B. and Chan, B., Footshock induced analgesia in mice: its reversal by naloxone and cross-tolerance with morphine, Life Sci., 21 (1977) 1569-1574.

6 Christie, M.J., Trisdikoon, P. and Chesher, G.B., Tolerance and cross tolerance with morphine resulting from physiological release of endogenous opiates, Life Sci., 31 rats repeatedly given the 4-min shock show no crosstolerance to the $1 \mathrm{~min}$ shock despite the fact that they obviously receive the 1 min shock daily within the 4-min paradigm. This lack of cross-tolerance between opioid ( $1 \mathrm{~min}$ ) and non-opioid ( $4 \mathrm{~min}$ ) forms of stress analgesia gives further evidence that their substrates are activated independently 32,36 . This finding also suggests, however, that an interaction occurs between these substrates. It has been proposed that collateral inhibition occurs between opioid and nonopioid pain-inhibitory systems ${ }^{12}$. Although in our studies neither opiate antagonists nor tolerance to opioids (e.g. morphine or opioid stress analgesia) have the potentiating effect on non-opioid stress analgesia predicted by this model, nonetheless, during the last $3 \mathrm{~min}$ of the 4-min footshock paradigm something happens to prevent the tolerance that would occur if the animal had received only the first min of footshock.

\section{ACKNOWLEDGEMENTS}

This work was supported by NIH Grant NS-07628 and a gift from the Brotman Foundation and NIMH Training Grant MH 15795 (G.W.T.).

(1982) 839-845.

7 D'Amour, F.E. and Smith, D.L., A method for determining loss of pain sensation, J. Pharmacol. Exp. Ther., 72 (1941) 74-79.

8 Grau, J.W., Hyson, R.L., Maier, S.F., Madden, J. IV and Barchas, J.D., Long-term stress-induced analgesia and activation of the opiate system. Science, 213 (1981) $1409-1410$.

9 Hayes, R.L., Bennett, G.J., Newlon, P.G. and Mayer, D.J., Behavioral and physiological studies of non-narcotic analgesia in the rat elicited by certain environmental stimuli, Brain Research, 155 (1978) 69-90.

10 Hutson, P.H., Curzon, G. and Tricklebank, M.D., Antinociception induced by brief footshock: characteristics and roles of 5-hydroxytryptamine and dopamine. In M.D. Tricklebank and G. Curzon (Eds.), Stress-Induced Analgesia, John Wiley, Chichester, 1984, pp. 135-164.

11 Keppel, G., Design and Analysis: A Researcher's Handbook, Prentice Hall, Englewood Cliffs. New Jersey, 1973.

12 Kirchgessner, A.L., Bodnar, R.J. and Pasternak, G.W., Naloxazone and pain-inhibitory systems: evidence for a collateral inhibition model. Pharmacol. Biochem. Behav. 17 (1982) 1175-1179.

13 Klein, M.V., Lovaas, K.M., Terman, G.W. and Liebeskind, J.C. The effects of decerebration and spinal transec- 
tion on three discrete forms of stress-induced analgesia. Soc. Neurosci. Abstr., 9 (1983) 795.

14 Kulkarni, S.K., Heat and other physiological stress-induced analgesia: catecholamine mediated and naloxone reversible response, Life Sci., 27 (1980) 185-188.

15 Levine. J.D., Gordon. N.C. and Fields, H.L., The mechanism of placebo analgesia, Lancet, ii (1978) 654-657.

16 Lewis, J.W. Cannon, J.T. and Liebeskind, J.C. Opioid and nonopioid mechanisms of stress analgesia. Science, 208 (1980) 623-625.

17 Lewis, J.W. Cannon, J.T. and Liebeskind, J.C., Involvement of central muscarinic cholinergic mechanisms in opioid stress analgesia, Brain Research, 270 (1983) 289-293.

18 Lewis, J.W.. Cannon, J.T., Stapleton, J.M. and Liebeskind, J.C. . Stress activates endogenous pain-inhibitory systems: opioid and nonopioid mechanisms, Proc. West. Pharmacol. Soc., 23 (1980) 85-88.

19 Lewis, J.W.. Sherman, J.E. and Liebeskind, J.C., Opioid and nonopioid stress analgesia: assessment of tolerance and cross-tolerance with morphine, J. Neurosci., I (1981) $358-363$.

20 Lewis, J.W., Terman, G.W., Nelson, L.R. and Liebeskind, J.C., Opioid and non-opioid stress analgesia. In M.D. Tricklebank and G. Curzon (eds.), Stress-Induced Analgesia, John Wiley, Chichester, 1984, pp. 103-134.

21 Lewis, J.W., Terman. G.W., Watkins, L.R., Mayer, D.J. and Liebeskind, J.C., Opioid and nonopioid mechanisms of footshock-induced analgesia: role of the spinal dorsolateral funiculus, Brain Research, 267 (1983) 139-144.

22 Lewis. J.W., Tordoff. M.G., Sherman, J.E. and Liebeskind, J.C., Adrenal medullary enkephalin-like peptides may mediate opioid stress analgesia, Science, 217 (1982) $557-559$.

23 Maier, S.F., Drugan, R.C. and Grau. J.W., Controlability. coping behavior, and stress-induced analgesia in the rat, Pain, 12 (1980) 47-56.

24 Maier, S.F., Sherman, J.E., Lewis, J.W., Terman, G.W. and Liebeskind, J.C. The opioid/nonopioid nature of stress-induced analgesia and learned helplessness, $J$. Exp. Psych.: Animal Behav. Processes, 9 (1983) 80-90.

25 Mayer, D.J., Price, D.D., Rafii, A. and Barber, J., Acupuncture hypalgesia: evidence for activation of a central control system as a mechanism of action. In J.J. Bonica and D. Albe-Fessard (Eds.), Advances in Pain Research and Therapy, Vol. 1, Raven Press. New York, 1976, pp. $751-754$.

26 Mayer. D.J., Wolfle, T.L., Akil, H., Carder, B. and Liebeskind, J.C.. Analgesia from electrical stimulation in the brainstem of the rat, Science, $174(1971) 1351-1354$.

27 McGivern, R.F., Berka, C., Berntson, G.G. Walker, J.M. and Sandman, C.A., Effect of naloxone on analgesia induced by food deprivation, Life Sci., 25 (1979) 885-888.

28 Miczek, K.A., Thompson, M.L. and Shuster. 1. Opioidlike analgesia in defeated mice, Science, 15 (1982) $1520-1522$.

29 Reynolds, D.V., Surgery in the rat during electrical analge sia induced by focal brain stimulation. Science. 164 (1969) 444-445.

30 Terman, G.W., Lewis, J.W. and Liebeskind, J.C.. Role of the biogenic amines in stress analgesia, Proc. West. Pharmacol. Soc., 25 (1982) 7-10.

31 Terman, G.W., Lewis, J.W. and Liebeskind, J.C., Evidence for the involvement of histamine in stress analgesia. Soc. Neurosci. Abstr., 8 (1982) 619.

32 Terman, G.W., Lewis, J.W. and Liebeskind, J.C., Opioid and nonopioid mechanisms of stress analgesia: lack of cross-tolerance between stressors, Brain Research, 260 (1983) 147-150.

33 Terman, G.W., Lewis, J.W. and Liebeskind, J.C., The sensitivity of opioid-mediated stress analgesia to narcotic antagonists, Proc. West. Pharmacol. Soc., 26 (1983) 49-53.

34 Terman, G.W. and Liebeskind, J.C., Differential effects of scopolamine on three forms of stress analgesia, Brain Research, 361 (1986) 405-407.

35 Terman, G.W., Penner, E.R. and Liebeskind, J.C., Stimulation-produced and stress-induced analgesia: cross-tolerance between opioid forms, Brain Research, in press.

36 Terman, G.W., Shavit, Y., Lewis, J.W.. Cannon, J.T. and Liebeskind, J.C., Intrinsic mechanisms of pain inhibition: activation by stress, Science, 226 (1984) 1270-127\%.

37 Watkins, L.R., Cobelli, D.A., Faris, P., Aceto, M.D. and Mayer, D.J., Opiate vs, nonopiate footshock-induced analgesia (FSIA): the body region shocked is a critical factor. Brain Research, 242 (1982) 299-308.

38 Watkins, L.R.. Katayama. Y.. Kinscheck, I.B., Mayer, D.J. and Hayes, R.L., Muscarinic cholinergic mediation of opiate and nonopiate environmentally induced analgesias, Brain Research, 300 (1984) 231-242.

39 Watkins, L.R. and Mayer, D.J., The organization of endogenous opiate and nonopiate pain control systems, Science, 216 (1982) 1185- 1192.

40 Young, R.F., Feldman, R.A., Kroening, R., Fulton, W. and Morris, J., Electrical stimulation of the brain in the treatment of chronic pain in man. In L. Kruger and J.C. Liebeskind (Eds.). Advances in Pain Research and Therapy, Vol. 6. Raven Press, New York, 1984, pp. 289-303. 